\title{
Spectrum of Liver Pathology in Autopsy Cases: A Study at Ajmer
}

\author{
Vandana Porwal, Deepali Jain*, Shweta Khandelwal, Seema Gupta and Aparna Rathi \\ Dept of Pathology, JLN MedicalCollege, Ajmer, Rajasthan, India
}

\begin{abstract}
Background: It is a known fact that silent liver diseases are common amongst apparently healthy individuals and are sometimes diagnosed only at autopsy The underlying causes of chronic liver diseases vary in different geographic areas and are based on various factors such as socioeconomic status, life style, diet, local or regional infections, and other endemic diseases.

Method: The present study was conducted in the Department of Pathology,J.L.N.Medical College, Ajmer during the period from January 2016 to September 2016 on 200 medico-legal autopsy cases brought to the mortuary Information regarding age, sex, place and previous history of any disease etc., were collected from the records and from the relatives. The liver specimens from these cases were examined grossly as well as microscopically to establish presence of liver diseases.

Results: Satisfactory tissue samples for histologic evaluation were available in all the cases with a mean age of 40.78 years. Males predominated the study with a male: female ratio of 4.4: 1 . Normal histology was found in $10(6.84 \%)$ cases. Important findings included congestion in 72 (49.21), steatosis in 58 (39.72\%), chronic hepatitis in $44(30.13 \%)$,steatohepatitis in $12(18.21 \%)$, cirrhosis in5(3.42\%)cases, hepatic granulomas in $4(3.8 \%)$ cases. Causes of death were: sudden deaths $(35.61 \%)$,old diseass $(13.69 \%)$,murder $(20.53 \%)$, insecticide spillage (7.53\%), Road traffic accident (5.47\%), alcohol poisoning (4.79\%), head injury $(2.70 \%)$.
\end{abstract}

Conclusion: The study was conducted only on specimens collected from the mortuary and may not reflect the actual pattern of liver diseases in the local.

Keywords: Autopsy, Liver Disease, Histopatholgy, Congestion

\section{Introduction}

Liver is vulnerable to a variety of metabolic, toxic, microbial and circulatory insults. Sometimes, the disease is primary while in others the hepatic involvement is secondary to cardiac de-compensation, alcoholism or extrahepatic infections. Quite rightly liver is, called as "the custodian of milieu interior". [1]

The major primary diseases of liver are circulatory disturbances, hepatic steatosis, alcoholic liver diseases and neoplasms. Most of the chronic liver diseases even in advanced stages may cause no prominent clinical signs or symptoms. They either go undiagnosed or are found incidentally during general health check-ups, investigations for other diseases, surgery, or at autopsy.

The main purpose of this study was to analyse different patterns of liver diseases that are reflected in the morphology of the liver at autopsy in Ajmer(Rajasthan) and to compare these patterns with other studies done in different parts of India \&world.

\section{Material and Method}

This study was done on the 200 autopsy specimens received in the histopathology section of Department of Pathology,
J.L.N. Medical College, Ajmer during the period of January 2016 to September 2016. Autolysed specimens (20) and specimens without liver (34) were excluded from the study. Rest autopsy specimens (146) irrespective of age, sex and cause of death were included in this study.

Liver specimens were received as a part of multiple viscera from mortuary for pathological examination. Rectangular pieces of liver along with bits of other organs were submitted to the histopathology section for evaluation. After fixation in $10 \%$ formalin, sections from representative area were submitted for processing. Sections were stained with H\&E stain and other special stains wherever necessary. Different findings of cases were analysed and expressed as frequencies and percentage.

\section{Results}

The study was conducted in the Department of Pathology, J.L.N. Medical College, Ajmer for a period of nine months, from January to September 2016.

The age wise distribution of the cases in the present study was wide from 18 months to 85 years. Mean age was 40.78 years. Maximum liver autopsies were in the age group 3140 years $(27.39 \%)$. [Table1] The male: female ratio in the 
present study was 4.4:1 showing preponderance of males ie. 33 cases $(22.06 \%)$. [Fig 1]

In the current study, the most common cause of death was sudden death- 52 cases (35.61\%) followed by previously diagnosed chronic diseases -22 cases (13.69\%). [Table2] Out of 146 cases, pathological lesions were noted in 136 (93.15\%) cases, while in remaining 10 cases $(6.84 \%)$ no pathology was seen. [Table3]

The most common pathological lesion noted was circulatory disturbances in the form of acute sinusoidal congestion and chronic venous congestion seen in 72 cases $(49.31 \%)$ followed by steatosis in $58(39.72 \%)$, chronic hepatitis

Table 1: Age Incidence.

\begin{tabular}{|c|c|c|c|c|}
\hline \multirow{2}{*}{ Age Group (Years) } & Male (Number) & Female (Number) & \multicolumn{2}{|c|}{ Total } \\
\cline { 3 - 5 } & & 2 & 3 & $2.05 \%$ \\
\hline $0-10$ & 1 & 1 & 5 & $3.42 \%$ \\
\hline $11-20$ & 21 & 11 & 32 & $21.91 \%$ \\
\hline $21-30$ & 33 & 7 & 40 & $27.39 \%$ \\
\hline $31-40$ & 28 & 5 & 33 & $22.60 \%$ \\
\hline $41-50$ & 19 & 0 & 19 & $13.01 \%$ \\
\hline $51-60$ & 8 & 0 & 8 & $5.47 \%$ \\
\hline $61-70$ & 4 & 1 & 5 & $3.42 \%$ \\
\hline $71-80$ & 1 & 0 & 1 & $0.68 \%$ \\
\hline Total & 119 & $\mathbf{2 7}$ & $\mathbf{1 4 6}$ & \\
\hline
\end{tabular}

Table 2: Cause of Death Distribution.

\begin{tabular}{|c|c|c|}
\hline Cause of Death & No. of Cases & Percentage \\
\hline Sudden Death & 52 & $13.61 \%$ \\
\hline Old disease & 22 & $12.32 \%$ \\
\hline Murder by weapon & 18 & $8.21 \%$ \\
\hline Murder by poisoning & 12 & $7.53 \%$ \\
\hline Insecticide spillage & 11 & $5.47 \%$ \\
\hline Road side accidents & 8 & $4.79 \%$ \\
\hline Alcohol poisoning & 7 & $2.70 \%$ \\
\hline Head Injury & 4 & $2.05 \%$ \\
\hline Hanging & 3 & $1.36 \%$ \\
\hline Snake bite & 2 & $1.36 \%$ \\
\hline Heat Stroke & 2 & $0.68 \%$ \\
\hline Railway track accidents & 1 & $0.68 \%$ \\
\hline Asphyxia & 1 & $0.68 \%$ \\
\hline Electric shock & 1 & $0.68 \%$ \\
\hline Burn & 1 & $0.68 \%$ \\
\hline Pregnancy complications & 1 & \\
\hline Total & 146 & \\
\hline
\end{tabular}

in $44(30.13 \%)$, cirrhosis in $05(3.42 \%)$, granulomatous hepatitis in $03(2.05 \%)$ and liver abscess in $1(0.68 \%)$ case. [Fig 2]

Age related changes which were observed in liver included increase in the number of binucleated cells and increased lipofuschin pigment in hepatocytes [Fig 3]. The pathological findings seen in burn cases included focal degeneration and necrosis of hepatocytes, proliferation of kupffer cells showing active phagocytosis. Inflammation, focal/centrilobular necrosis was seen in poisoning cases. Postmortem cases with history of diabetes mellitus showed glycogen vacuoles within nucleus. [Fig 4] 
Table 3: Comparison studies in India.

\begin{tabular}{|c|c|c|c|c|c|c|}
\hline $\begin{array}{l}\text { Types of } \\
\text { Hepatic Lesion }\end{array}$ & $\begin{array}{l}\text { Salem, Tamil } \\
\text { Nadu (Tamil } \\
\text { Selvi et al) }\end{array}$ & $\begin{array}{c}\text { Kolar, Karnataka } \\
\text { (Umesh Babu R } \\
\text { et al) }\end{array}$ & $\begin{array}{l}\text { Imphal, Assam } \\
\text { (Ph. Madhubala } \\
\text { Devi et al.) }\end{array}$ & $\begin{array}{l}\text { Patiala, Punjab } \\
\text { (M.S. Bal et al.) }\end{array}$ & $\begin{array}{c}\text { Solapur, } \\
\text { Maharashtra } \\
\text { (Smita et al) }\end{array}$ & $\begin{array}{l}2017 \text { Present } \\
\text { study }\end{array}$ \\
\hline Congestion & $16.70 \%$ & $9.52 \%$ & $5.00 \%$ & $9.00 \%$ & $29.05 \%$ & $49.31 \%$ \\
\hline Steatosis & $26.90 \%$ & $22.90 \%$ & $17.00 \%$ & $30.00 \%$ & $15.52 \%$ & $39.72 \%$ \\
\hline Hepatitis & $13.90 \%$ & $20.90 \%$ & $22.00 \%$ & $3.00 \%$ & $21.29 \%$ & $38.35 \%$ \\
\hline Cirrhosis & $7.40 \%$ & $1.90 \%$ & $25.00 \%$ & $14.00 \%$ & $4.43 \%$ & $3.42 \%$ \\
\hline $\begin{array}{l}\text { Hepatic } \\
\text { Granuloma }\end{array}$ & - & $3.80 \%$ & - & - & $3.10 \%$ & $2.05 \%$ \\
\hline Hepatic abscess & $7.40 \%$ & - & - & $2.00 \%$ & - & $0.68 \%$ \\
\hline Tumours & $1.90 \%$ & - & - & $3.00 \%$ & $2.88 \%$ & - \\
\hline Normal & $25.90 \%$ & $4.76 \%$ & $11 \%$ & $30.00 \%$ & $21.51 \%$ & $6.84 \%$ \\
\hline Autolysed & - & - & - & - & - & $13.69 \%$ \\
\hline
\end{tabular}

Table 4: Histopathological Findings.

\begin{tabular}{|c|c|c|}
\hline Histopathological Findings & No. of Cases & Percentage \\
\hline Congestion & 72 & $49.31 \%$ \\
\hline Steatosis & 58 & $39.72 \%$ \\
\hline Steatohepatitis & 12 & $18.21 \%$ \\
\hline Chronic hepatites & 44 & $30.13 \%$ \\
\hline Bile ductular proliferation & 7 & $4.79 \%$ \\
\hline Cirrhosis & 5 & $3.42 \%$ \\
\hline Hepatic granuloma & 3 & $2.05 \%$ \\
\hline Hepatic abscess & 1 & $0.68 \%$ \\
\hline Normal & 10 & $6.84 \%$ \\
\hline
\end{tabular}

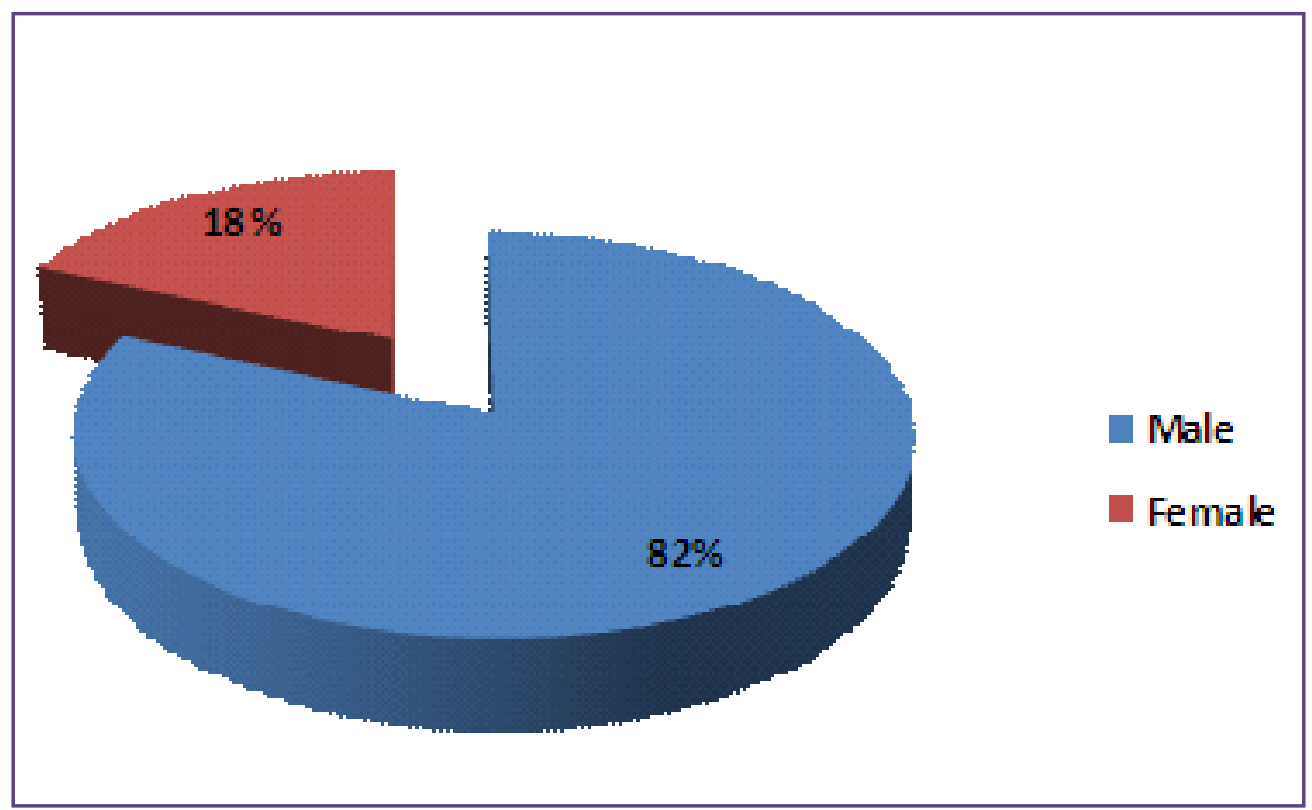

Fig. 1 : Gender Distribution. 


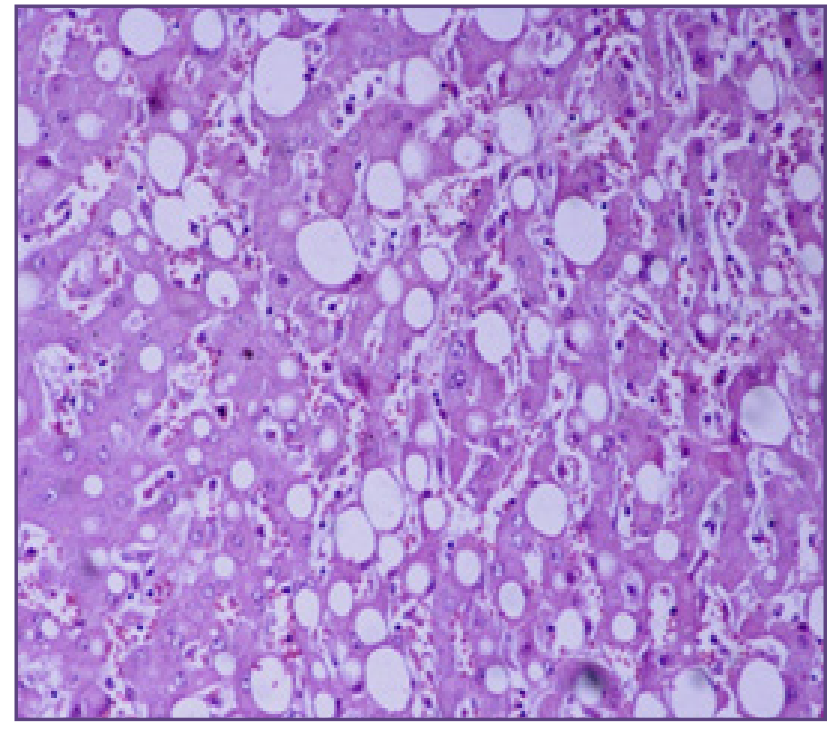

Fig. 2: Microphotograph showing diffuse macrovesicular steatosis( H\& E stain, 200X).

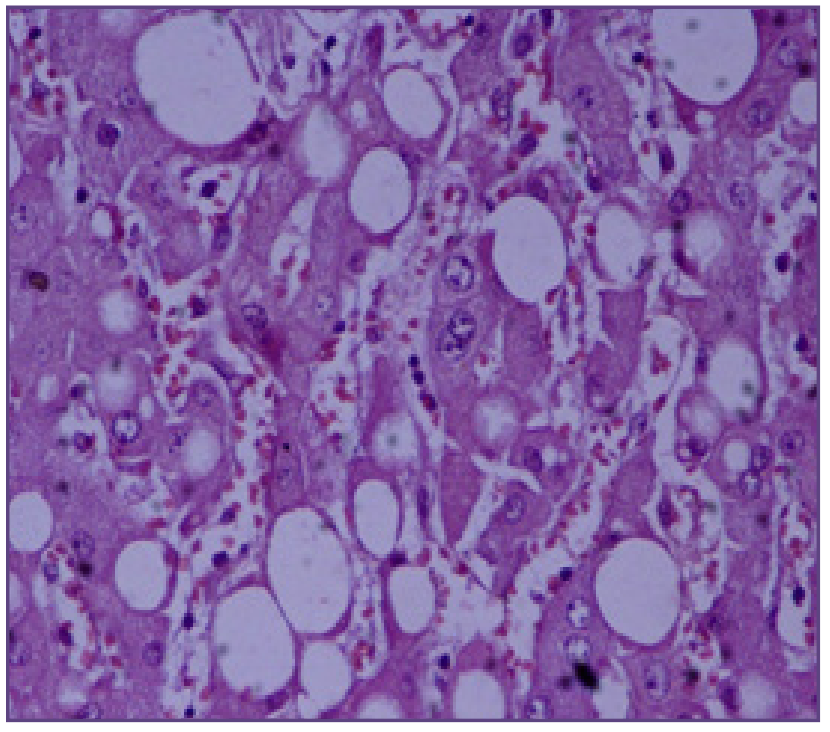

Fig. 3: Microphotograph showing bilobed nucleus in hepatocytes( H\& E stain, 400X).

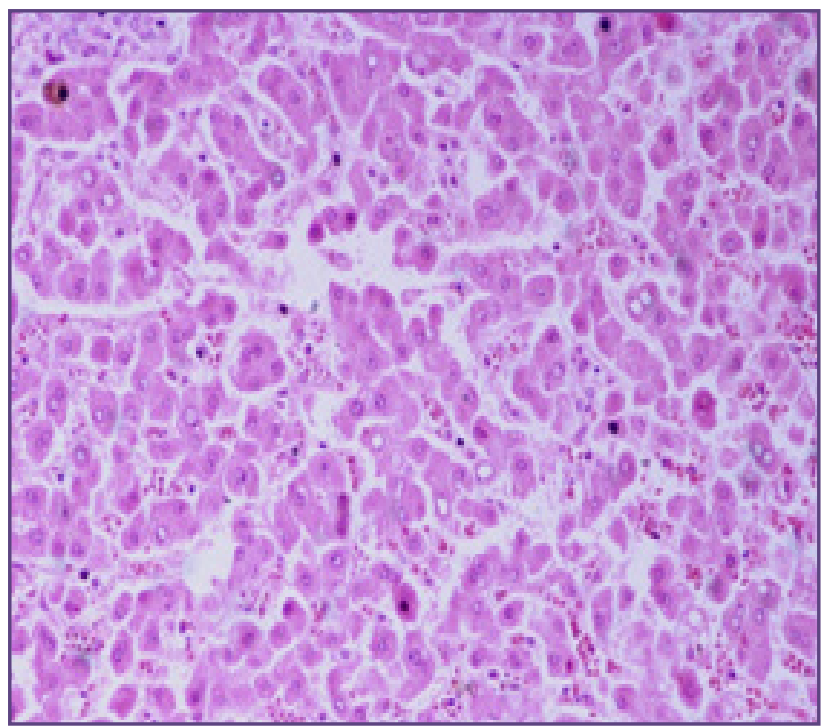

Fig. 4 Microphotograph showing glycogen vacuoles within the nucleus of hepatocytes( H\& E stain 200X).

\section{Discussion}

The importance of histopathology in diagnosing liver diseases cannot be overemphasised as some may remain silent and diagnosed only at autopsy. In studies conducted by Bal MS et al ${ }^{[2]}$ and Fubara $\mathrm{S}$ et al ${ }^{[3]}$ it was observed that the commonest affected age group was $41-50$ years $(53.85 \%)$ and $41-49$ years $(28 \%)$ respectively which is comparable to the findings of the present study. Liver diseases predominated in males in the present study which was in concurrence with the findings of several workers ${ }^{[2-6]}$ and this may be attributed to the fact that men indulge themselves more to alcohol and smoking as compared to women.
In the study of 4908 autopsy cases from Russia, the most frequent hepatic lesions were Steatosis and Inflammatory disorders. ${ }^{[7]}$ Berry in 1500 autopsies performed in the coronal system in South-East London reported Cirrhosis, Adenoma, Metastatic carcinoma and Hamartoma as the most common findings. Space occupying lesions were found in about $5 \%$ of livers in that study. ${ }^{[8]}$

Another study based on analysis of 1839 necropsies in Singapore revealed that unanticipated liver lesions are common. The most important once were cholelithiasis, cirrhosis, and primary carcinoma of the liver. ${ }^{[9]}$ 
In contrast to these studies conducted abroad, Circulatory disturbances, Steatosis and Chronic hepatitis were frequent hepatic lesions in our study which is quite comparable to studies done in different states of India. [Table 4]

Venous congestion of liver is seen in most of the liver autopsies. The present study revealed circulatory disturbances in the form of acute and chronic venous congestion in $48.9 \%$ cases in contrast to $29.05 \%$ and $16.7 \%$ cases as reported by Smita $\mathrm{S}$ et al ${ }^{[10]}$ and Tamil Selvi $\mathrm{R}$ et al ${ }^{[5]}$ in their studies conducted in Solapur (Maharashtra) and Salem (Tamil Nadu) respectively.

Steatosis of liver was a frequent histological finding seen in routine autopsies in association with other histological features or as the only structural abnormality. Umesh R et al ${ }^{[11]}$ and Madhubala Devi et al ${ }^{[12]}$ found $22.9 \%$ and $17 \%$ prevalence of steatosis in their studies conducted in Kolar (Karnataka) and Imphal (Assam) respectively, which is comparable with present study $(39.72 \%)$.

Surprisingly the most common pathological lesion in studies by Madhubala Devi et al ${ }^{[12]}$ is Cirrhosis. This is in contrast to other studies in India and present study where Steatosis and Congestion were the common pathological lesions. [Table 4]

Granulomas are frequently encountered in liver biopsies and their existence captures the attention of clinicians and pathologists. ${ }^{[13]}$ They are found virtually in all patients with disseminated tuberculosis. ${ }^{[14]}$ Drugs are an important cause of otherwise unexplained granulomas. They are sometimes the only or main manifestation of a drug reaction but can also form part of cholestasis or hepatitis picture. In the study by Cunnigham et al they have detected granuloma in $2-10 \%$ of liver biopsies in large series. ${ }^{[14]}$

In our study $2.05 \%$ cases showed the presence of hepatic granulomas which is comparable with study by Smita $\mathrm{S}$ et al $(3.10 \%){ }^{[10]}$ and Umesh $\mathrm{R}$ et al $(3.80 \%) .{ }^{[1]]} \mathrm{All}$ cases in present studies were known case of Pulmonary Tuberculosis.

Extra hepatic bacterial infections, particularly sepsis can induce mild hepatic inflammation and varying degrees of hepatocellular cholestasis. In severe cases it may even cause cell necrosis and abscess formation.

Both benign and malignant, epithelial as well as mesenchymal neoplasms arise in liver. Of the malignant tumors, metastatic tumors are more common than primary tumors. But in the present study not a single neoplastic lesion was found.

The difference in frequencies of various lesions in these studies may be due to difference in sample size, age group and patterns of study. Most of the studies are conducted on bits of liver or whole liver in forensic autopsies who are relatively young subjects and usually in better health conditions and may not reflect the actual pattern of liver diseases in the local population. In more than $70 \%$ of the cases the cause of death was acute event. While very few studies included only clinical autopsies done on hospitalized patients and as per clinical interest.

\section{Conclusion}

Finally we conclude that histopathological study of liver is a magnificent learning tool in the hands of pathologists to study the spectrum of liver diseases which is a great value in improving the vision and diagnostic setup for clinical assessment. In our autopsy cases based study chronic venous congestion was the most common liver pathology followed by steatohepatitis. Although autopy based studies do not reflect the actual pattern of liver diseases but emphasizes the need of further studies for early detection and treatment of vulnerable groups.

\section{References}

1. Rezek R Philipp and Max Millard. Autopsy pathology; a guide for pathologists and clinicians: Springfield, Thomas ;1963: 464-467.

2. Bal MS, Singh SP, Bodal VK, Oberoi SS, Surinder K. Pathological findings in liver autopsy. Journal of Indian Academy of Forensic Medicine 2004; 26(2):971-73.

4. Sotoudehamanesh R, Sotoudeh M, Asgari A, AbediArdakani B, Tavangar SM, Khakinejad A et al. Silent liver diseases in autopsies from forensic medicine of Tehran. Archives of Iranian Medicine 2006; 9(4):324-28.

3. Fubara DS, Jebbin NJ. Hepatocellular carcinoma in Port Harcourt, Nigeria.Clinicopathologic study of 75 Cases. Annals of African Medicine 2007; 6(2):54- 7.

5. Selvi RT, Selvam V, Subramanium PM. Common silent liver diseases in and around of Salem population: An autopsy study. Journal of Clinical and Diagnostic Research 2010 Apr; 6(2):207-10.

6. Merat S, Sotoudehmanesh R, Nouraie M, Peikan-Heirati M, Sepanlou SG, Malekzadeh R et al. Sampling error in histopathology findings of non alcoholic fatty liver diseases: A postmortem liver histology study. Archives of Iranian Medicine 2012 July; 7:418-20.

7. Voinova LV. Aetiological and nosological structure of liver diseases (on autopsy data of clinics of I.M. Sechenov Moscow Medical Academy in 1988-1997). Arkh patol. 2000; 62:45-47.

8. Berry CL. Liver lesions in an autopsy population. Hum Toxicol. 1987; 6: 209-214.

9. Lee YS. The pattern of liver diseases in Singapore. An autopsy study. Trop Geogr Med. 1979; 31:69-74. 
10. Smita et al. Study of liver pathology in autopsy cases. International Journal of Current Research 2014 ; 6 (3) : 5795-5797.

11. Umesh Babu et al .Spectrum of liver pathology at autopsy. IJRR 2015; 2 (3):79-85.

12. Madhu Bala devi et al. Pathological findings of liver in autopsy cases, A study at Imphal. J Indian Acad Forensic
Med 2013 ;35(3):206-210.

13. Zumla A, James DG. Granulomatous infections: Etiology and Classification. Clin Infect Dis. 1996;23:146-58.

14. Cunnigham D, Mills PR, Quigley EM, Patrick RS, Watkinson G, MacKenzie JF. Hepatic Granulomas: Experience over a 10-year period in the West of Scotland. Q J Med. 1982;51:162-70.

*Corresponding author:

Dr. Deepali Jain, House No 1246/32, Dadabhai Colony, Nasirabad Road, Ajmer 305001(Rajasthan) India

Phone: +919784639491

Email: deepalijain_1411@yahoo.co.in

Financial or other Competing Interests: None. 